\title{
Mitigation of operational losses in matrix converter fed DFIG for WECS
}

\author{
Haroon Ashfaq ${ }^{*}$ and Surendra Kumar Tripathi
}

\begin{abstract}
With the change in the wind profile, the speed of doubly fed induction generator (DFIG) of wind energy conversion system (WECS) changes from super synchronous to sub synchronous range and vice versa. DFIG is operated to generate quality power; hence, power at rotor side is controlled using matrix converter taking power from grid and feeding back power to the grid depending on the wind profile. Input voltage required to be fed to the rotor side of DFIG is always changing and depends on the speed of the available wind. During the operation when power is fed from grid to rotor of DFIG, a high-voltage stress continues across the switches of power electronic converter (PEC). In existing topologies of the matrix converter used with the DFIG in WECS, the constant voltage stress at the power electronic switch (PES) is available which causes the higher losses across the switch. This also causes common mode voltage (CMV) which leads to the over voltage stress. This may cause winding insulation damage and bearing failure of the DFIG. Furthermore, higher $\mathrm{dv} / \mathrm{dt}$ of CMV raises the leakage current which causes the thermal stress and electromagnetic noise to the equipments installed near the matrix converter. In this paper, the work done is focused on the mitigation of operational losses in matrix converter fed doubly fed induction generator for wind energy conversion system. The overall loss in the matrix converter and mitigation of common mode voltage is achieved, which improves the overall efficiency and the performance of the wind energy conversion system.
\end{abstract}

Keywords: Wind energy conversion system; Matrix converter; Doubly fed induction generator; Power electronic converter; Common mode voltage

\section{Introduction}

In recent time, the application of power electronic converter in wind energy conversion system has increased. This not only increased the penetration of wind power in power system but also the reliability of operation. Various power converters are reported to be used with doubly fed induction generator (DFIG) to ensure the continuous quality power generation from wind-based power-generating unit.

The standard power electronic interface used with DFIG is two back-to-back voltage source inverters (VSI) with an intermediate dc link and capacitor (Merahi and Berkouk 2013). This demands a complicated control strategy and bulky dc link capacitor. The output current waveforms are deviated from being sinusoidal. Due to bulky electrolytic capacitor, the space occupied by the converter is more. The other disadvantage of back-to-

\footnotetext{
* Correspondence: harun_ash@yahoo.com

Department of Electrical Engineering, Faculty of Engineering and Technology, Jamia Millia Islamia, New Delhi 110025, India
}

back converter is that at low frequency, the value of output current is low as the current is not equally shared among the switches of the converters. The electrolytic capacitor used as a dc link in back-to-back converter has deteriorate performance at high temperature, hence the reliability of converter is not considered to be good (Cardenas et al. 2013; Cárdenas et al. 2013a; Cárdenas et al. 2012; Han et al. 2013).

But in recent years, an increasing interest in developing direct frequency power converter has taken place, like matrix converter, indirect matrix converter, and sparse matrix converter etc. (Merahi and Berkouk 2013). This recently developed silicon based ac-ac converter has the advantage of sinusoidal input and output current without using passive component in the dc link.

Among the entire converters used with DFIGs, the matrix converter is known to be the universal energy processor. Matrix converter is a forced commutated ac-ac converter which requires an array of controlled bidirectional power electronic switch (PES) to generate variable

\section{Springer}


output voltage based on the wind profile. Due to the application of matrix converter, the performance improvement of wind energy conversion system has been achieved (Hamane et al. 2012; Pena et al. 2011; Taib et al. 2013). With the increase of the application of power electronic converter (PEC) in wind energy conversion system, the net penetration of wind power in power system is increasing significantly. In spite of various advantages, the mostly reported disadvantage is the higher switching losses and conduction losses. Research work is being carried out to estimate the conduction losses and switching losses and their relation with switching frequency, modulation techniques, current ripple, etc. In various research work carried out globally, for reduction of losses, the increased switching frequency and a combination of continuous and discontinuous modulation with distribution of the clamping segments in accordance to the load phase angle were proposed (Cárdenas et al. 2013b; Ghatpande et al. 2013; Ghoudelbourk et al. 2012; Yin et al. 2005).

The most important characteristics of matrix converter include simple and compact power circuit. It also has the capacity to generate the load voltage with arbitrary amplitude and frequency. Operation at unity power factor with sinusoidal input and output currents and regeneration capability is the major advantage. Due to various attractive characteristics, the matrix converter has the reasons for the tremendous interest.

The relevant control and modulation methods developed so far for the matrix converter has been shown in the Figure 1. The matrix converter control which includes the direct transfer function approach is well known as the Venturini method. In this method, the output voltage is obtained by the product of the input voltage and the transfer matrix which represents the converter. Another strategy is the scalar method which was developed by Roy; this consists of using the instantaneous voltage ratio of input phase voltages, which generate the active and zero states of the converter's switches. The important solution for the control of matrix converter is achieved from the use of pulse width modulation (PWM) technique which was previously developed for voltage source inverters. The simplest approach is to use carrierbased PWM techniques. A very elegant and powerful solution currently in use is to apply space vector modulation (SVM) in matrix converters. An alternative solution is direct torque and flux control, which has also been proposed for the speed control of an ac machine driven by the matrix converter. Various modern techniques, such as predictive control, have recently been proposed for the current and torque control of ac machines using matrix converter. The control strategies based on PWM methods which allow for output voltage regulation while maintaining unity power factor on the input side have been applied to different kinds of matrix converters, as has been reported in various research papers (Venturini 1980; Roy and April 1989; Lopez Arevalo et al. 2010; Yoon and Sul 2006; Casadei et al. 2002; Ormaetxea et al. 2011; Xiao and Rahman 2009; Vargas et al. 2008a; Vargas et al. 2008b; Rodriguez et al. 2010).

The space vector approach is based on the instantaneous space vector representation of input and output voltages and currents. The SVM technique for matrix converter has the inherent capability to achieve full control of both the output voltage vector and the instantaneous input current displacement angle. The matrix converter using SVM technique has a reduced resonance in the input filter. Carrier-based PWM method does not take care of the quality of the input current originate strong resonances in the input filter.

In this paper, due to the abovementioned factors, the space vector modulation technique is adopted with matrix converter for wind energy conversion system. Higher switching loss is the major drawback of the matrix converter application. Also, the wind profile changes, and the switching and conduction of engaged PEC is also affected. In this paper, a modified matrix converter topology using space vector modulation is proposed which have low conduction losses and switching losses. In addition,

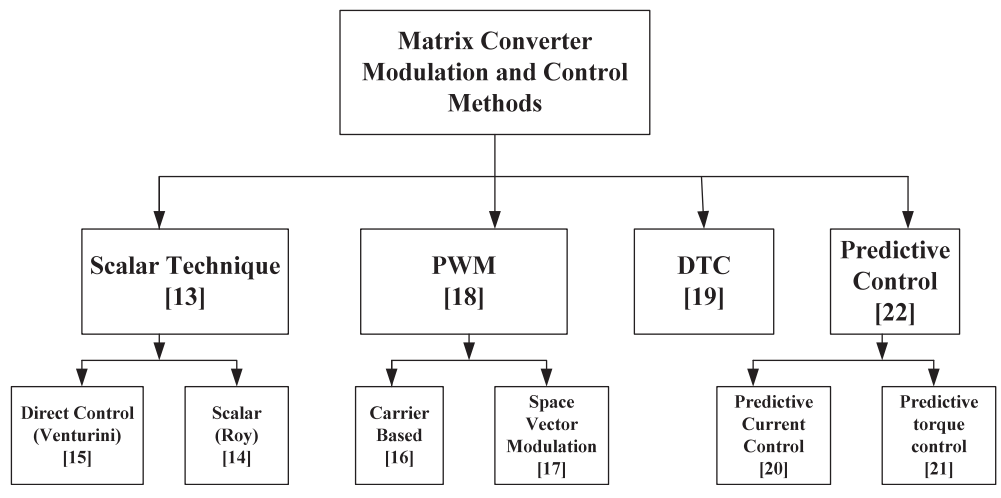

Figure 1 Matrix converter modulation and control methods. 
the voltage stress across the semiconductor devices of power converter is also reduced even though the wind profile is fluctuating. The proposed topology also reduces common mode voltage (CMV) hence low thermal stress on the winding of DFIG. This approach has the advantages like low switching and conduction losses, mitigation of common mode voltage, and overall improvement in the efficiency and the performance of the wind energy conversion system. For this purpose, the virtual dc link voltage of the modified converter topology is controlled according to the speed of DFIG and is kept at value of required rotor voltage. In this paper, the change in virtual dc link voltage with wind profile is proposed. In the proposed work, the dc link voltage is controlled on the basis of corresponding wind profile.

\section{Methods}

Analysis and review of matrix converter performance Application of matrix converter with suitable maximum power point tracking (MPPT) technique with DFIG of wind energy conversion system (WECS) improves the performance. Continuous observation of DFIG speed is performed and close loop feedback is to be obtained. Matrix converter connected between the rotor of DFIG and grid fed power to the rotor of DFIG during sub synchronous operation. During super synchronous operation condition, the power is fed to the grid from rotor of DFIG is known as slip power recovery. During the operation when power is fed from grid to rotor of DFIG, a high-voltage stress continues across the switches of PEC (Ugalde-Loo et al. 2013; Blaabjerg et al. 2012; Garcés and Molinas 2012; Ashfaq and Tripathi 2012; Soufi et al. 2013). Hence high dc voltage exists; this is also a factor responsible for the CMV. The CMV causes the over voltage stress to the winding insulation of DFIG and increased thermal losses. CMV is dependent on the virtual dc link voltage of the proposed power electronic converter. If the virtual dc link voltage of the proposed converter is changed, the CMV will also change (Lee and Sul 2001; Swamy et al. 2001; Wei et al. 2004; Holmes 1996; Lee et al. 2010; Yue et al. 2006; Arifujjaman 2013; Ponmani and Rajaram 2013). Requirement of rotor voltage also varies with respect to slip value which is governed by the wind characteristics.

Matrix converter employed with WECS accommodates any input and output power factor independent of each other. This also controls the switching and injection of harmonics in the system which arises due to gusts in available wind (Ghatpande et al. 2013). Losses are reduced in the proposed work by applying the vector modulation and clamp switching strategy. This is controlling the virtual dc link voltage and eliminating the voltage stress across the PES. Modulation strategy is based on the space vector modulation.

The rotor voltage of DFIG depends on the operating slip, stator voltage, and the stator to rotor turn ratio. Therefore, the required virtual dc link voltage also changes with the slip. Thus, more the deviation from the synchronous speed, higher is the virtual dc link voltage value.

The proposed system shown in Figure 2 having two subsections of proposed matrix converter engaged in power control, the current source rectifier (CSR) and VSI, their role interchanges as power flows from grid to rotor or vice versa. Wind speed sensor is employed to continuously monitor the speed of wind turbine. The corresponding slip calculation on the basis of current operating speed is performed by the slip calculator unit connected in the proposed system. On the basis of input obtained from monitoring system, the required rotor voltage calculation is performed by rotor voltage calculator unit. All this input is fed to the control unit to determine the SVM strategy and pulse generation for controlled operation. This regulates the virtual dc link voltage which fluctuates due to gusts or variation in the wind profile depending on the geographical and environmental conditions.

\section{Proposed control system overview for stable operation}

Wind profile continuously changes with respect to time; hence, the controlling of matrix converter employed with DFIG in WECS also varies accordingly. Due to this increase in on loss, off loss and conduction loss in power electronic switch and CMV effect in DFIG are observed with fluctuations in wind profile. CMV may cause machine winding insulation failure and bearing deterioration. To reduce the CMV, small and medium positive line to line voltage is employed to generate dc link voltage in rectifier stage, and suitable zero vector is chosen during inverter stage. Hence, the virtual dc link voltage of the converter is controlled to neutralize the impact of variation in wind velocity.

Since the required rotor voltage always changes with the slip value, hence, the required rotor current keeps changing and depends on the required rotor voltage due to the gusts and fluctuations in the available wind. In the proposed scheme (as shown in Figure 3), the virtual dc link voltage is controlled referring the wind profile. Hence, on the basis of wind profile, the output voltage of the matrix converter connected to grid side is controlled and the suitable switching strategy developed is employed. To control the operation of matrix converter, various control and modulation techniques like space vector modulation, direct torque control, singular value decomposition modulation, input power factor compensation, etc. are used. Space vector modulation technique 


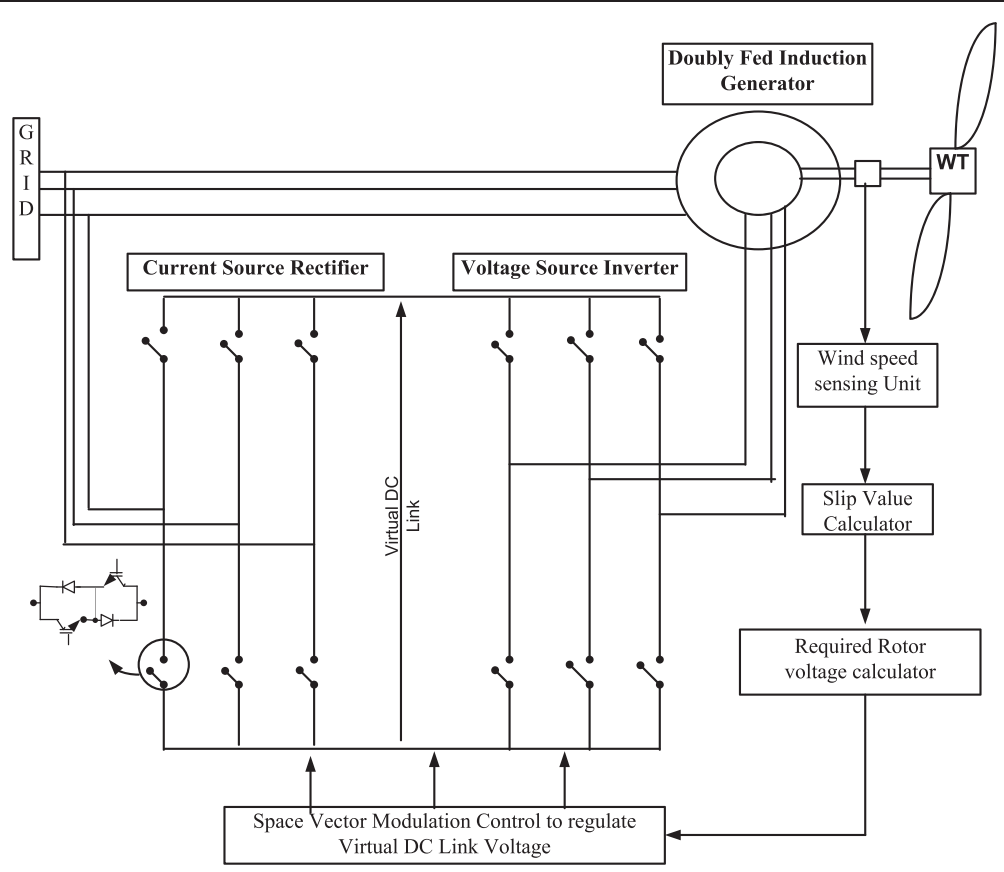

Figure 2 Simplified representation of proposed system.

is employed here. With the application of the proposed strategy of controlling the dc link voltage, both supply and rotor side voltage and current are obtained sinusoidal. Virtual dc link voltage is controlled in such a way that the voltage stress across the switches remains as low as possible which will help in reducing the on losses, off losses, and the conduction losses in the power electronic switches. This also controls the CMV and reduces the thermal stress on the DFIG rotor windings.

On the basis of the rotor speed, the slip value is calculated and the corresponding instantaneous rotor voltage is calculated. This instantaneous rotor voltage value is compared with the previous recorded rotor voltage. The compared value and the virtual dc link voltage are fed to

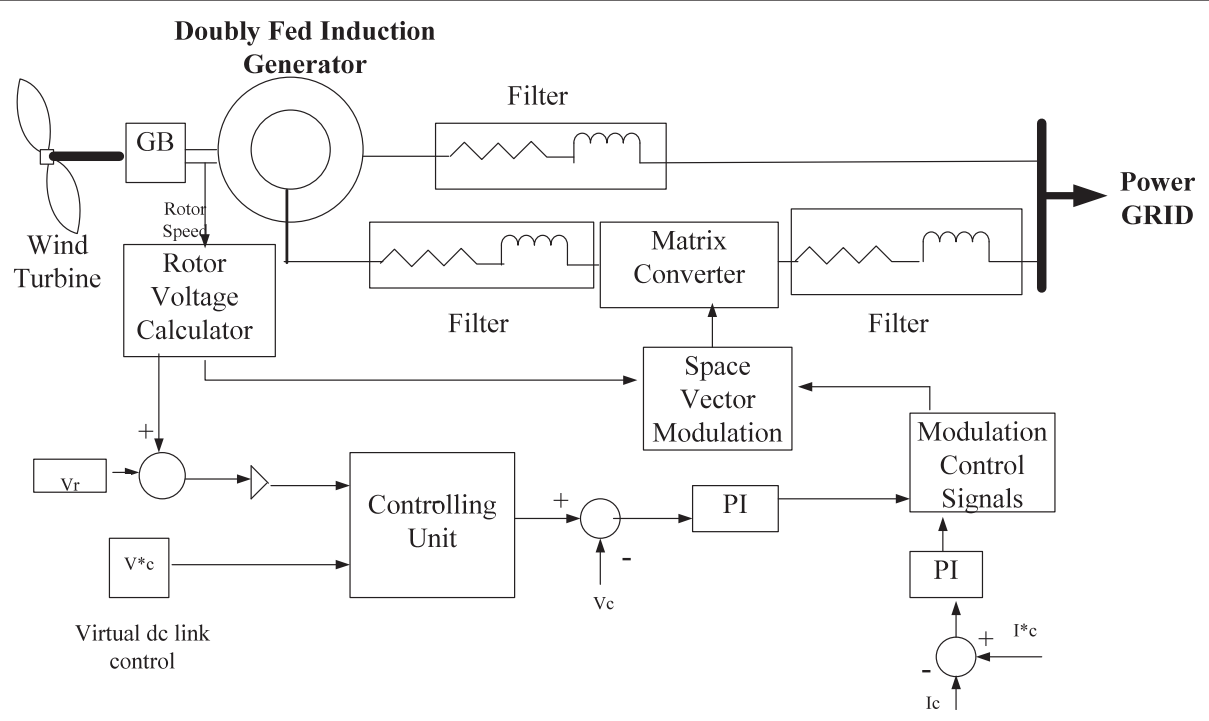

Figure 3 Proposed wind energy conversion system control. 
the controlling unit. On the basis of the voltage and current signals, the modulation control signals are generated to control the matrix converter.

As seen from the Figure 3, the virtual dc link voltage and rotor voltage signals are fed to the controlling unit. The signal from controlling unit and $V_{c}$ value is used to generate the reference voltage signal to be fed to the modulation control signal unit. Similarly, the second PI controller is used to generate the reference current signal to be fed to the modulation control signal unit. The modulation control signal unit generates the signal to be fed to the space vector modulation unit on the basis of received reference voltage and reference current signals. The space vector modulation unit processes the signal received from the modulation control signal unit and the signal from the rotor voltage calculator. The signals generated from space vector modulation unit control the switching and operation of the matrix converter which is a major contribution by this paper. Since the large disturbances and noise is expected due to variable wind profile, hence, the forced oscillations and steady-state errors are eliminated in this process.

Current and voltage at the output side are controlled by controlling the duty cycle of the switches. The relations between voltage and current are justified by following equations:

$$
\begin{aligned}
& \mathrm{V}_{A B C}=\mathrm{S} \cdot \mathrm{V}_{a b c} \\
& \mathrm{I}_{a b c}=\mathrm{S}^{T} \cdot \mathrm{I}_{A B C}
\end{aligned}
$$

Where $V_{\mathrm{ABC}}=$ output voltage

$V_{\mathrm{abc}}=$ input voltage
$I_{\mathrm{ABC}}=$ output current

$I_{\mathrm{abc}}=$ input current

$$
S=\left[\begin{array}{lll}
S_{11} & S_{12} & S_{13} \\
S_{21} & S_{22} & S_{23} \\
S_{31} & S_{32} & S_{33}
\end{array}\right]
$$

$S_{11}-S_{33}$ is duty cycle of corresponding switches of matrix converter.

\section{Proposed modulation and switching scheme for matrix converter operation}

Proposed MC topology is an equivalent combination of an input virtual rectifier and the output virtual inverter connected to a virtual dc link. Virtual rectifier is controlled as classical current source rectifier and virtual inverter as the classical voltage source inverter. Bidirectional CSR is cascaded to VSI without any intermediate energy storage element physically present. The intermediate voltage is 'virtual dc link voltage.'

Selections of modulation strategy and switching pattern of PEC also have impact on the output power quality which is a major concern in the wind based power generation.

Proposed scheme for the control with space vector modulation is shown in Figure 4. The proposed scheme for the control of virtual dc link voltage is shown in Figure 5 and its corresponding space vector diagram of the CSR is shown in Figure 6. The space vector modulation is based on the instantaneous space vector representation of input and output voltage and current space vector as discussed in Figure 3. There are 27 allowed states in a matrix converter taking in account the input

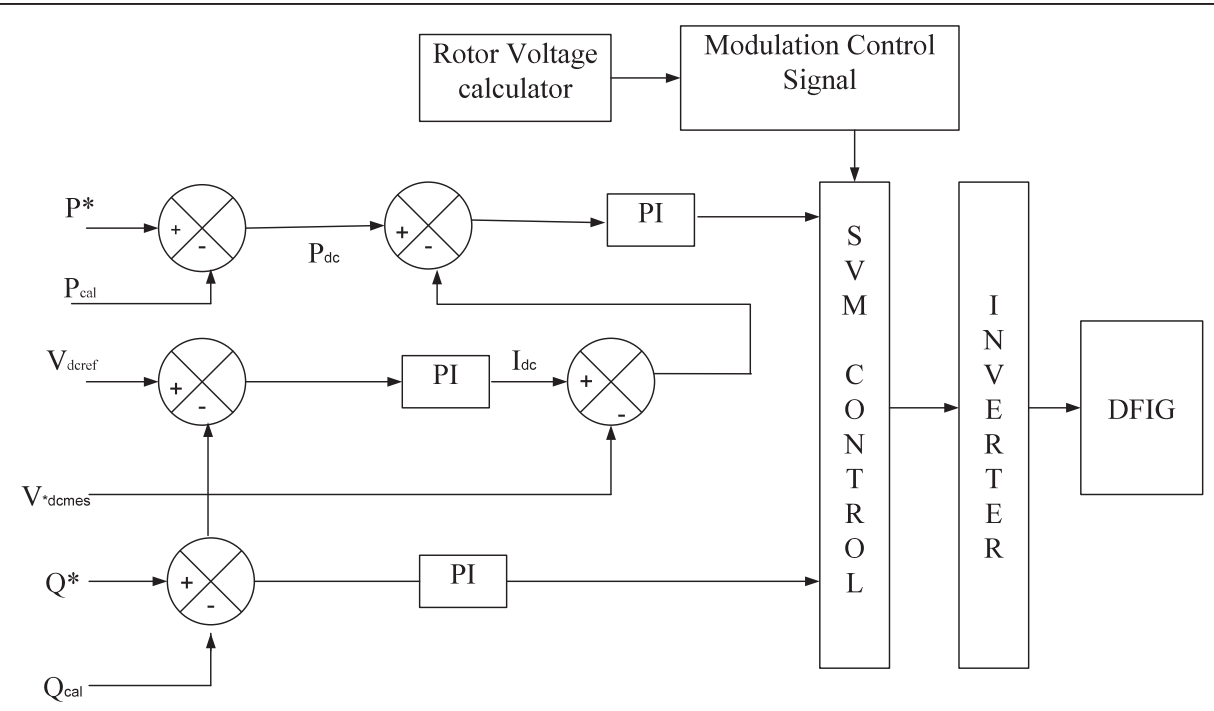

Figure 4 Control with space vector modulation. 


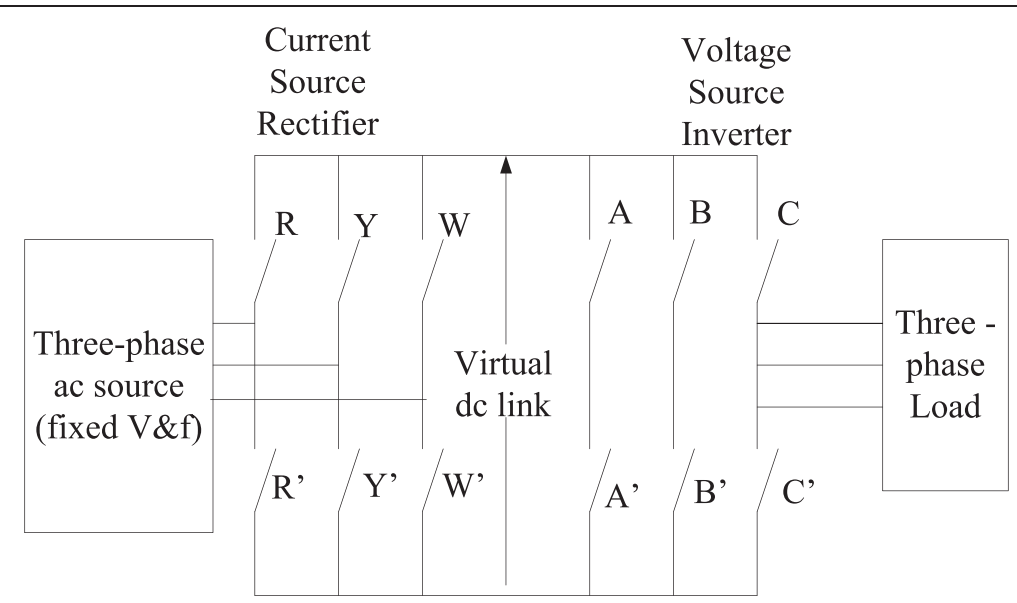

Figure 5 Proposed scheme for virtual DC link voltage control.

short circuit output open circuit restraints. Out of these, 24 states are active vectors and 3 states are zero vector. Out of these 24 states of active vector, 18 states are stationary vector and 6 states are rotating vector. Therefore, in 27 possible switching configurations, 21 are applied in which 18 switching configurations determine an output voltage vector and input current vector having fixed directions. The 18 switching configurations determine the space vector as shown in Figure 6 . The remaining 3 switching configurations determine zero input current and output voltage vector. Switching pattern is defined on the basis of the scalar comparison of input phase voltage and the instantaneous value of the desired output voltage which depends on the DFIG operation profile. At any given sampling time, the voltage vector and current displacement angle are known as reference quantity. The control of the input side can be obtained by controlling the phase angle value of the current vector. The current and voltage vectors are generated by referring

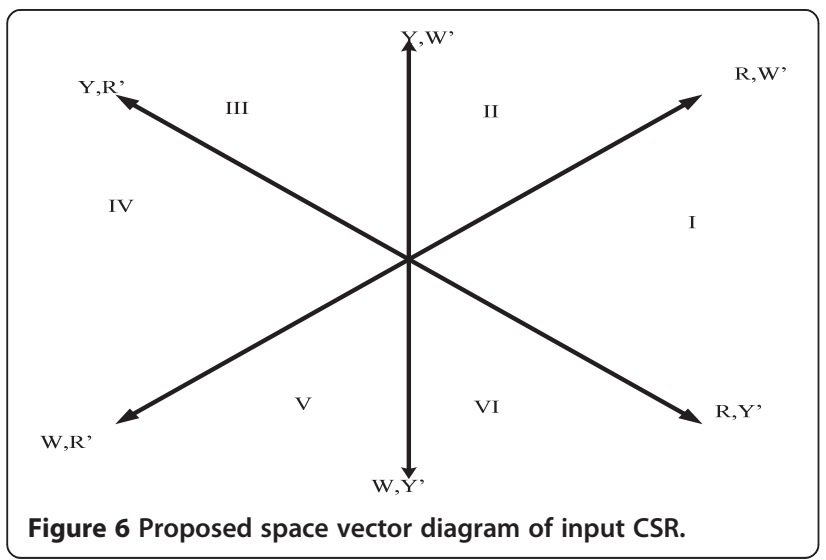

the duty cycle which is determined by phase of output voltage and input current vector references.

Proposed space vector diagram shows the sector definitions and commutation sequence to obtain the virtual dc link voltage. Table 1 shown below defines the sequence of switches to be clamped and modulated. Upper switch of any one phase is kept at $\mathrm{ON}$ state and the lower switches of remaining phases are modulated. This gives the multiple dc link voltage values as per the requirement. The magnitude of virtual dc link voltage is defined by modulated switch.

The converter is controlled by modulating the CSR with always one upper switch and one lower switch on. The upper and lower switches are from the same input phase which gives the freewheeling state to dc; this gives the minimum average dc voltage. To get the maximum average dc link voltage, the switches are selected from the different phases.

The modulated switches and virtual dc link voltage over a period is controlled using proposed switching and modulation strategy. The proposed technique ensures the proper selection of zero space vectors in the inverter stage which is resulting in the significant reduction in the peak

Table 1 Proposed switching combination and virtual DC link voltage

\begin{tabular}{llllll}
\hline Sextant & $\begin{array}{l}\text { Clamped } \\
\text { switch }\end{array}$ & $\begin{array}{l}\text { Modulated } \\
\text { switches }\end{array}$ & \multicolumn{2}{l}{$\begin{array}{l}\text { Virtual DC } \\
\text { link voltage }\end{array}$} \\
\hline 1 & $\mathrm{R}$ & $\mathrm{Y}^{\prime}$ & $\mathrm{W}^{\prime}$ & $\mathrm{V}_{\mathrm{RY}}$ & $\mathrm{V}_{\mathrm{RW}}$ \\
2 & $\mathrm{~W}^{\prime}$ & $\mathrm{R}$ & $\mathrm{Y}$ & $\mathrm{V}_{\mathrm{RW}}$ & $\mathrm{V}_{Y W}$ \\
3 & $\mathrm{Y}$ & $\mathrm{W}^{\prime}$ & $\mathrm{R}$ & $\mathrm{V}_{Y W}$ & $\mathrm{~V}_{Y R}$ \\
4 & $\mathrm{R}^{\prime}$ & $\mathrm{Y}$ & $\mathrm{W}$ & $\mathrm{V}_{Y R}$ & $\mathrm{~V}_{W R}$ \\
5 & $\mathrm{~W}$ & $\mathrm{R}^{\prime}$ & $\mathrm{Y}^{\prime}$ & $\mathrm{V}_{W R}$ & $\mathrm{~V}_{W Y}$ \\
6 & $\mathrm{Y}^{\prime}$ & $\mathrm{W}$ & $\mathrm{R}$ & $\mathrm{V}_{W Y}$ & $\mathrm{~V}_{\mathrm{RY}}$ \\
\hline
\end{tabular}


value of common mode voltage. The reduction of peak value of CMV is achieved up to $1 / \sqrt{3}$ times of the CMV obtained in conventional techniques of control.

In the proposed work, the modulation technique used involves the six switching pattern with changes and also clamps the output phase which is having the major absolute current. By adopting this technique, the decrement in the switching losses and increment in the converter efficiency is achieved.

In Table 1, the sequence of clamed switch and modulated switches is defined to determine the virtual dc link voltage. Determination of phase voltages as shown in Figure 5 is defined as follows.

Voltage across the switch $\mathrm{R}$ is given as:

$$
\mathrm{V}_{R}=\mathrm{V}_{m} \cos \theta_{R}
$$

Where $\mathrm{V}_{m}=$ input voltage amplitude and $\theta_{R}$ is phase angular displacement.

Similarly, the voltage across the switch $\mathrm{Y}$ is given as:

$$
\mathrm{V}_{Y}=\mathrm{V}_{m} \cos \theta_{Y}
$$

Where $\mathrm{V}_{m}=$ input voltage amplitude and $\theta_{Y}$ is phase angular displacement.

And the voltage across the switch $\mathrm{W}$ is given as:

$$
\mathrm{V}_{W}=\mathrm{V}_{m} \cos \theta_{W}
$$

Where $\mathrm{V}_{\mathrm{m}}=$ input voltage amplitude and $\theta_{\mathrm{W}}$ is phase angular displacement.

Thus:

$$
\mathrm{V}_{R}+\mathrm{V}_{Y}+\mathrm{V}_{W}=0
$$

Figure 7 gives the reference phasor crossing over during transition of sextant as proposed in Table 1. Proposed sequence of replacement of states for peak sampling and through sampling is defined in such a way that distortion of the waveform be null or minimum possible. At point 'a' as shown in Figure 7, sextant transition occurs from sextant 6 to sextant 1 . At point ' $b$ ', the first carrier peak is obtained and the switch transition occurs; moving further at point ' $c$ ', the carrier peak value is achieved. Section between ' $b$ ' and ' $c$ ' causes the narrow switching pulses which may cause the malfunctioning of the PES. Therefore, the value of $\delta_{b}$ is minimized in the proposed work. At point 'd,' again, the switching transition takes place as occurred at point ' $b$ ' hence at point 'e, the sextant transition occurs and is repeated so on to points 'f', 'g', 'h', etc.

Narrow pulse is avoided by controlling the value of $\delta_{b}$ and is done in the proposed work. To minimize the switching losses, CSR is commutated at points 'b', 'd,' ' $\mathrm{f}$ ', ' $h$ ', and so on as dc link current is null or minimum at these points.

\section{Proposed loss mitigation technique for matrix converter}

Matrix converter operates at higher frequency to improve the output characteristics. Since the virtual dc link voltage also varies with respect to the wind profile as the required rotor side voltage in the DFIG varies, this increases the application of high switching frequency to keep the voltage and current sinusoidal; hence, the switching losses are more due to gusts and variable characteristics of wind. Switching losses are required to be reduced for performance enhancement. In case of the forced commutation, the losses are high. In this paper for the reduction of the losses and increase of switching frequency, a combination of the continuous and discontinuous modulation and distribution of the clamping segment in accordance to the load phase angle is proposed.

Conduction losses in the PES are the function of collector current $\left(I_{\mathrm{C}}\right)$ and the collector emitter voltage $\left(V_{\mathrm{CE}}\right) \quad$ (www.datasheetarchive.com/matrix\%20converter-datasheet.html; www.datasheets.org.uk/bidirectional\%20switch\%20igbt\%20matrix\%20c;

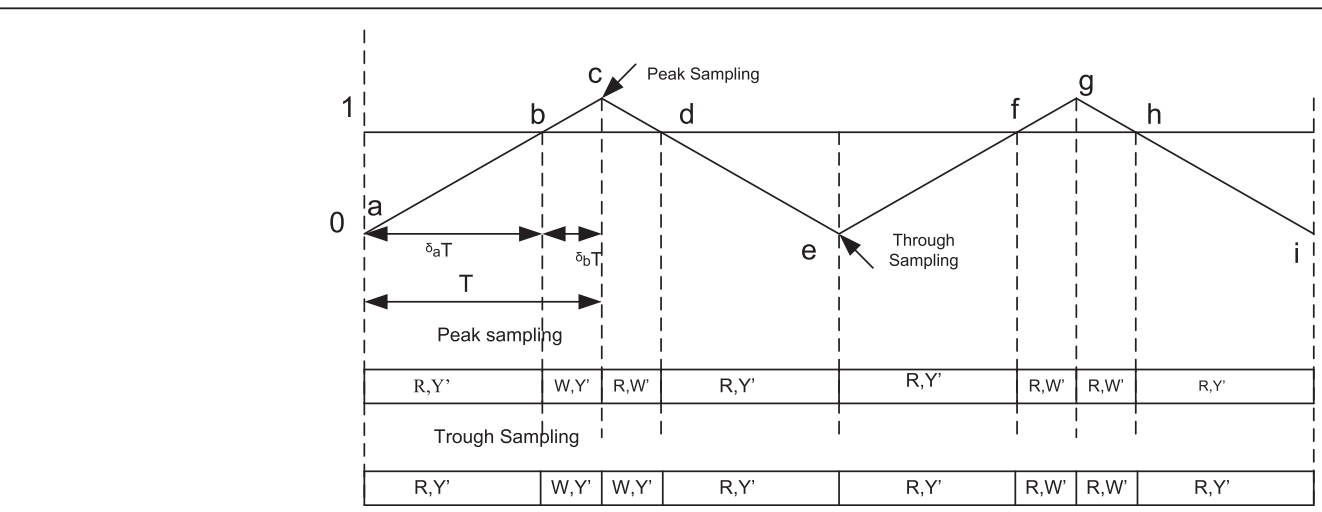

Figure 7 Proposed sampling scenario during sextant transition. 


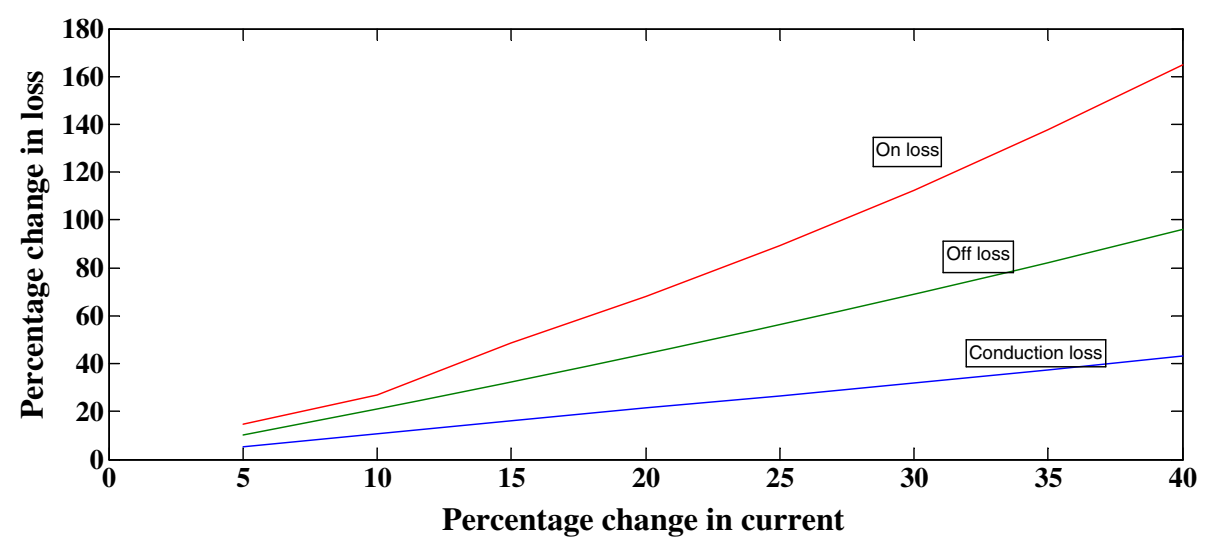

Figure 8 Relation between percentage change in loss with respect to load current of DFIG.

www.alldatasheet.com; www.igbt.cn/UserFiles/Support_IGBT/file_057.pdf; pdf.datasheetcatalog.com/datasheet/.../mXyzxuz.pdf; www.datasheetarchive.com):

$$
\mathrm{V}_{C E}=A+B . I_{C}+C \cdot I_{C}{ }^{2}
$$

Losses in the converter are due to switch on, switch off, and conduction of the switches. The turn on loss of the PES depends on various parameters like on time, voltage across the switch, resistance, etc. Similarly, the off and conduction losses are also dependent on abovementioned parameters as well as the switching frequencies. The abovementioned parameters are determined on the basis of wind profile and characteristics.

Thus, the conduction losses $P_{\text {cond }}$ are dependent on the switch parameters and are defined as:

$$
\mathrm{P}_{\text {cond }}=\frac{1}{T} \int_{t_{0}}^{t_{o}+T} \mathrm{~V}_{C E} \cdot \mathrm{I}_{C} \cdot d t
$$

Energy dissipated Esw in each switching action of PES:

$$
\mathrm{E}_{s w}=\mathrm{f}_{k 1} \cdot \mathrm{I}_{C}^{2}+\mathrm{f}_{k 2} \cdot \mathrm{I}_{C}
$$

Where $f_{\mathrm{k} 1}$ and $f_{\mathrm{k} 2}$ are considered to be nonlinear function of blocking voltage and the type of switching losses considered.

Switching losses are determined by the instantaneous value of dc link voltage and current which varies with wind characteristics. In the proposed work, these losses are minimized by providing lowest and the second largest input line to line voltage for the formation of the converter virtual dc link voltage.

In the case of the traditional control strategy, the dc link voltage is kept constant. Therefore, the calculated conduction and switching losses are high as demonstrated from above equations. These losses are dependent on the voltage value. In the case of the proposed work, the virtual dc link voltage is changing as per the required rotor voltage governed by the wind profile. Therefore, the net loss component decreases which results in the efficiency enhancement of the converter. In comparison to the traditional method, the loss component is low in the proposed method which depends on the load current as shown in Figure 8. The net reduction of 32\% in loss component is achieved using the proposed technique of virtual dc link voltage control.

In the proposed work, the magnitude of virtual dc link voltage is controlled on the basis of wind profile. This value keeps changing with respect to the wind profile, hence the voltage stress across the PES also keeps changing. DFIG is forced to operate at speed near to synchronous. Hence on losses, off losses, conduction losses, and the energy dissipated in the switching action are also minimized by controlling the value of $V_{\mathrm{CE}}$ and $I_{\mathrm{C}}$.

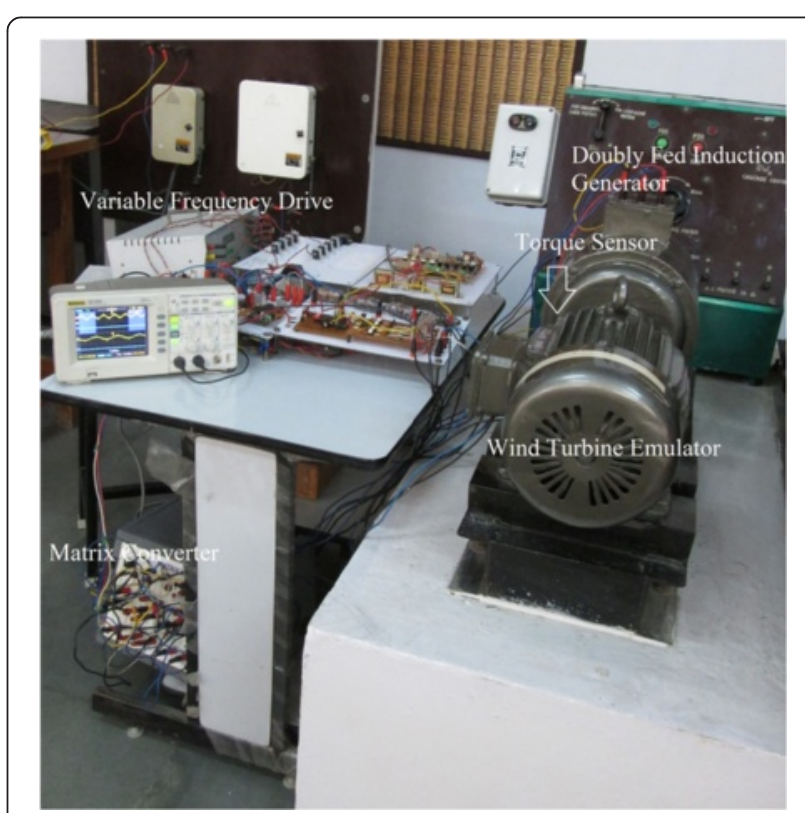

Figure 9 WECS prototype using DFIG with matrix converter. 


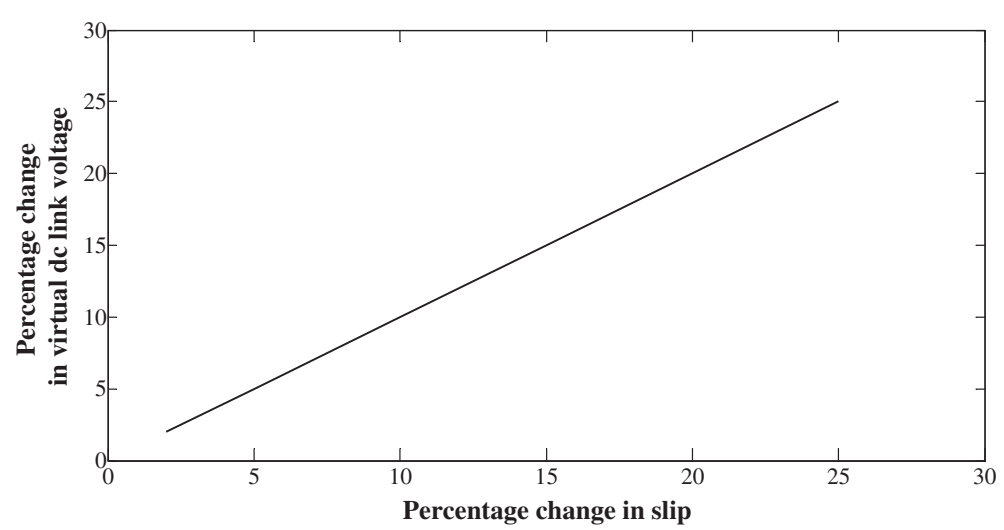

Figure 10 Relation between virtual dc link voltage and slip of DFIG.

In the proposed work, the virtual dc link voltage is controlled to reduce the loss component simultaneously the CMV also changes. With the change in the CMV, the total harmonic distortion (THD) also gets effected. It is found that this is a kind of trade off between the rms value of CMV and THD of input current. The harmonic mitigation is achieved as the design filters connected with the matrix converter ensures that no harmonics are introduced to the system and provide the unity power factor with no harmonic current injection. This insures the maximum possible harmonics mitigation.

It is found that if the virtual dc link voltage is controlled and kept low when high rotor voltage is not required, the load current will also change accordingly. As calculated from equation number 7,8 , and 9 , the net operational losses will reduce down. In the proposed work, the virtual dc link voltage is kept low when possible. This reduces the voltage stress across the power electronic switches; as a result, the operational losses are reduced. This is achieved using the proposed modulation and switching scheme discussed in the paper.

\section{Results and discussion}

The work proposed in the paper is for a grid interactive WECS, hence to validate the proposed topology, modulation strategy and control of power electronic converter shown in Figure 3 is simulated using MATLAB/ simulink. To verify the proposed performance improvement of WECS, the following system configuration is simulated. DFIG with $P_{\mathrm{g}}=1.5 \mathrm{MW}, R_{\mathrm{s}}=0.012 \Omega, R_{\mathrm{r}}=$ $0.021 \Omega, L_{\mathrm{s}}=L_{\mathrm{r}}=0.0137 \mathrm{H}, M=0.0135 \mathrm{H}, J=50 \mathrm{~kg} \mathrm{~m}^{2}$, $p=2, f=0.00071 \mathrm{Nms} / \mathrm{rd}, V_{\mathrm{g}}=690 \mathrm{~V}$ is simulated using proposed matrix converter with parameters as $P_{\max }=$ $7.5 \mathrm{~kW}, V_{\mathrm{CES}}=1,200 \mathrm{~V}, I_{\mathrm{C} \_ \text {nom }}=35 \mathrm{~A}$ having input filter parameters $C_{\mathrm{F}}=4.7 \mu \mathrm{F}(305 \mathrm{~V}), L_{\mathrm{F}}=1.6 \mathrm{mH}(16 \mathrm{~A}), R_{\mathrm{d}}=$ $33 \Omega(11 \mathrm{~W}), R_{\mathrm{pu}}=47 \Omega(11 \mathrm{~W}, 220 \mathrm{~V})$ and clamp circuit

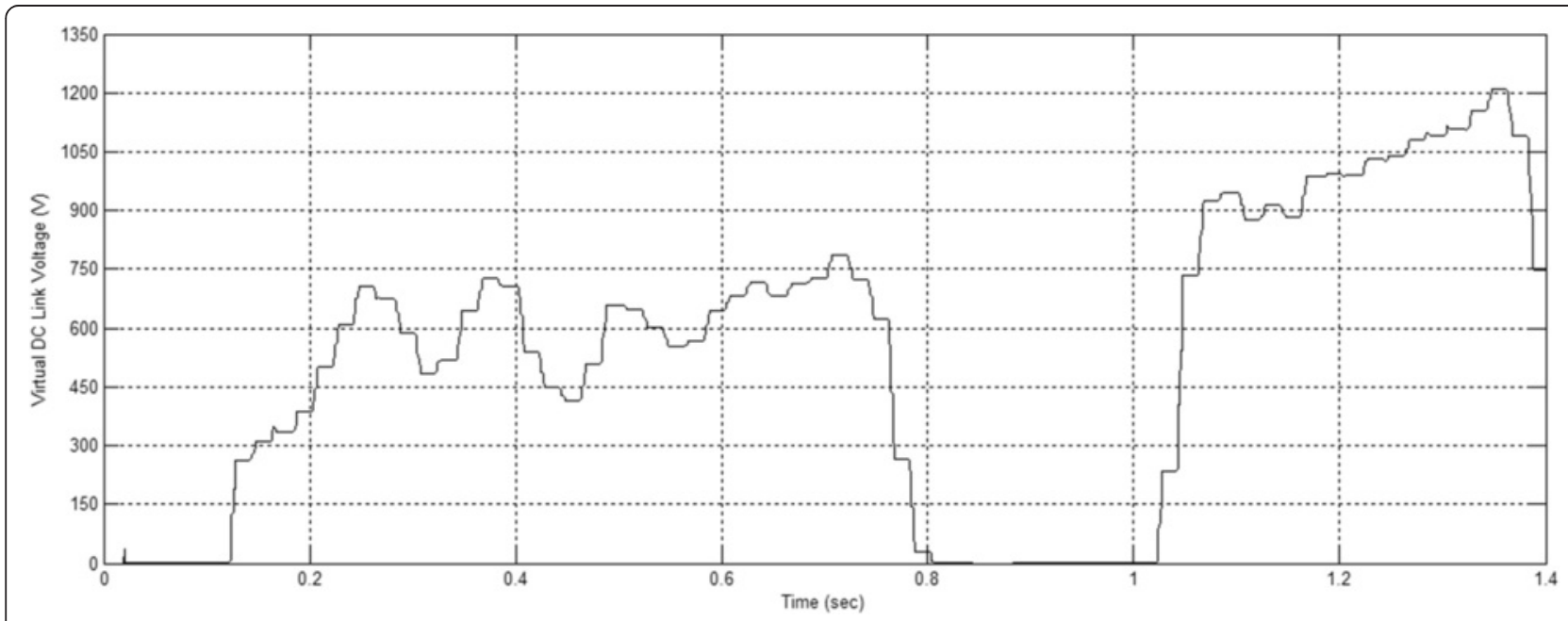

Figure 11 Virtual DC link voltage. 


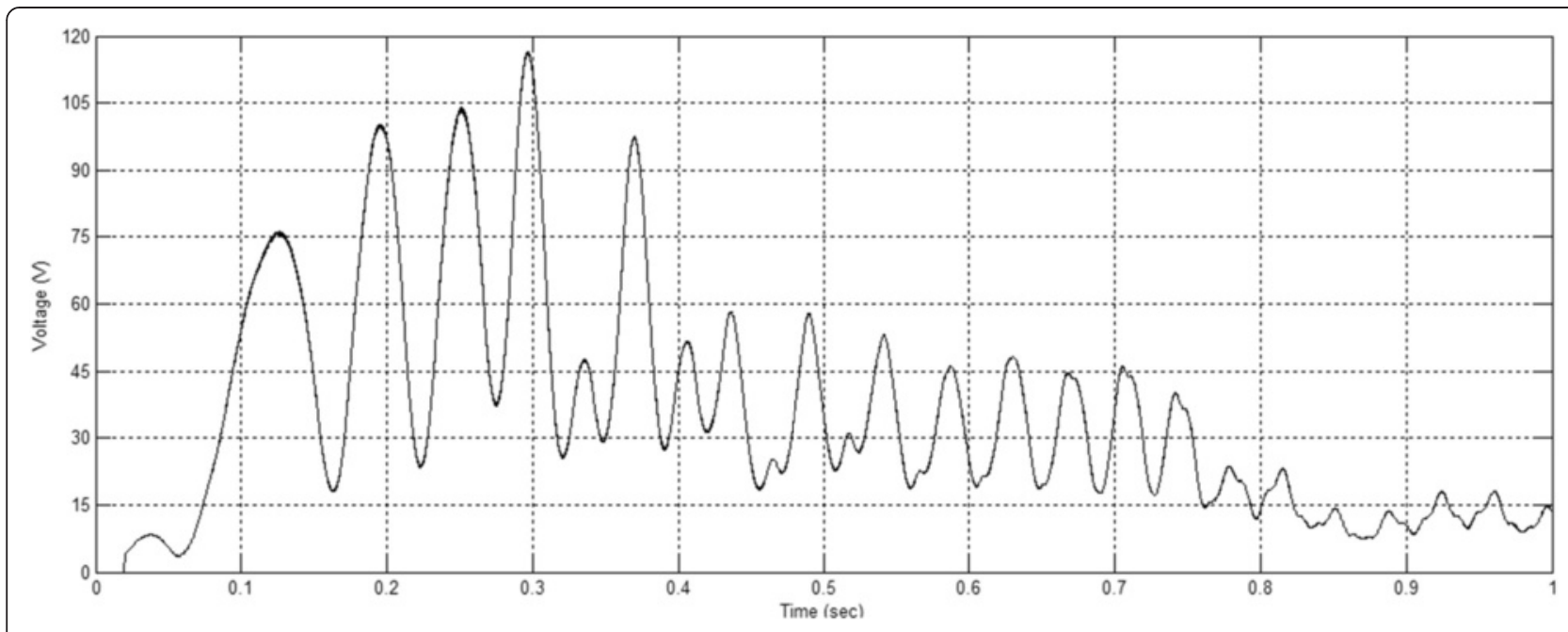

Figure 12 Common mode voltage (traditional method).

parameters as $C_{\text {clamp }}=2 \times 270 \mu \mathrm{F}(450 \mathrm{~V}), R_{\text {clamp }}=2 \times 47$ $\mathrm{K} \Omega(10 \mathrm{~W})$. The control and modulation of the proposed matrix converter is done using SVM technique.

The abovementioned system is also validated with the help of a prototype of wind energy conversion system using DFIG with matrix converter as shown in Figure 9. Variable frequency drive (VFD) controlled induction motor is used as a wind turbine emulator. A two channel $50 \mathrm{MHz}$ digital oscilloscope of RIGOL make (DS1052E model) is used for observation and measurement of results. The DFIG used in the experimental setup has four poles with rated power of $3.7 \mathrm{~kW}$. The rated current and voltage are $7.5 \mathrm{~A}$ and $415 \mathrm{~V}$, respectively.

The simulation results prove that the proposed technique achieves the objective of controlling the virtual dc link voltage to reduce the losses in the operation of matrix converter significantly. In the proposed work, the PEC is replaced by the modified matrix converter with control of virtual dc link voltage as per the DFIG operation profile. It has been observed that net losses of the converter are reduced. Figure 10 represents the relation between change in slip with respect to required change in virtual dc link voltage of the modified matrix converter. It is analyzed and concluded from the simulation results that the on loss, conduction loss, and off loss component increases with increase of current. This is validated with help of equation number 9 and simulation result represented in the Figure 8.

Voltage required across the rotor of DFIG is wind profile dependent, hence the current required also varies. Net power loss is minimized by controlling the virtual dc link voltage as per the requirement. Reduction in on

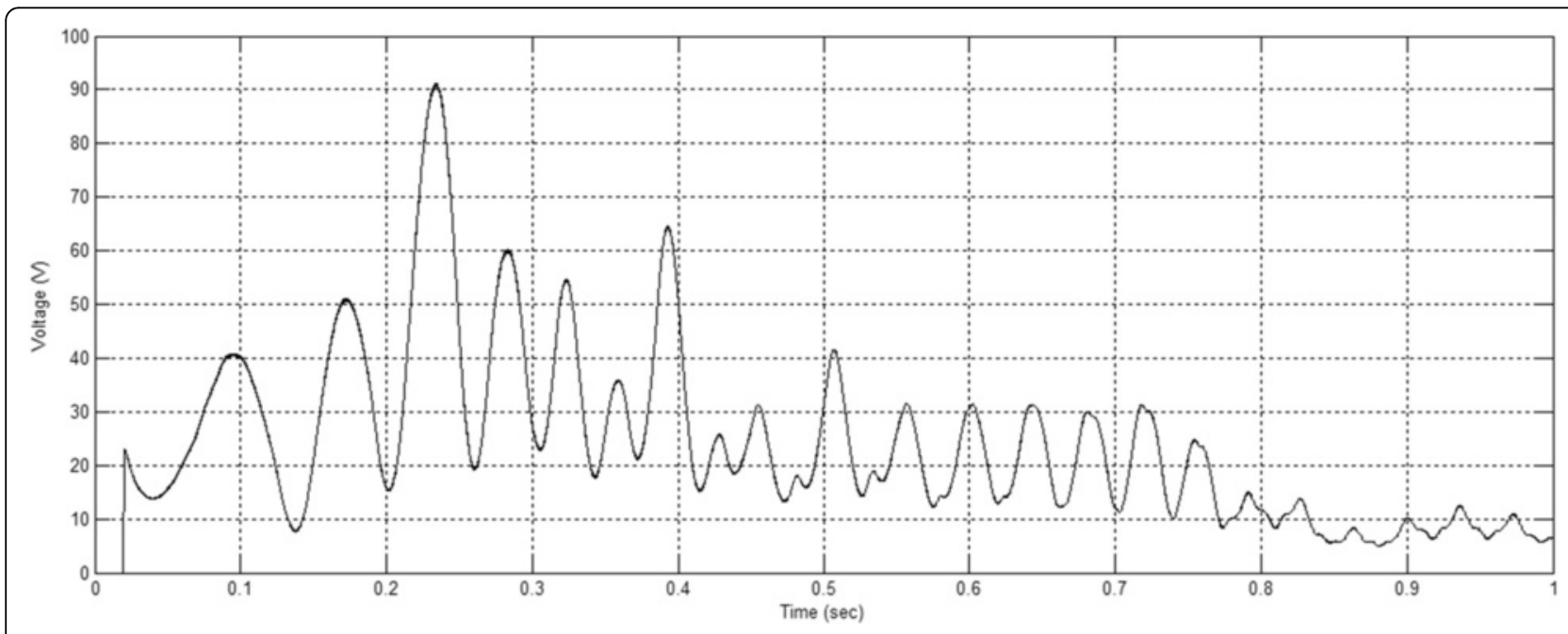

Figure 13 Common mode voltage (proposed method). 


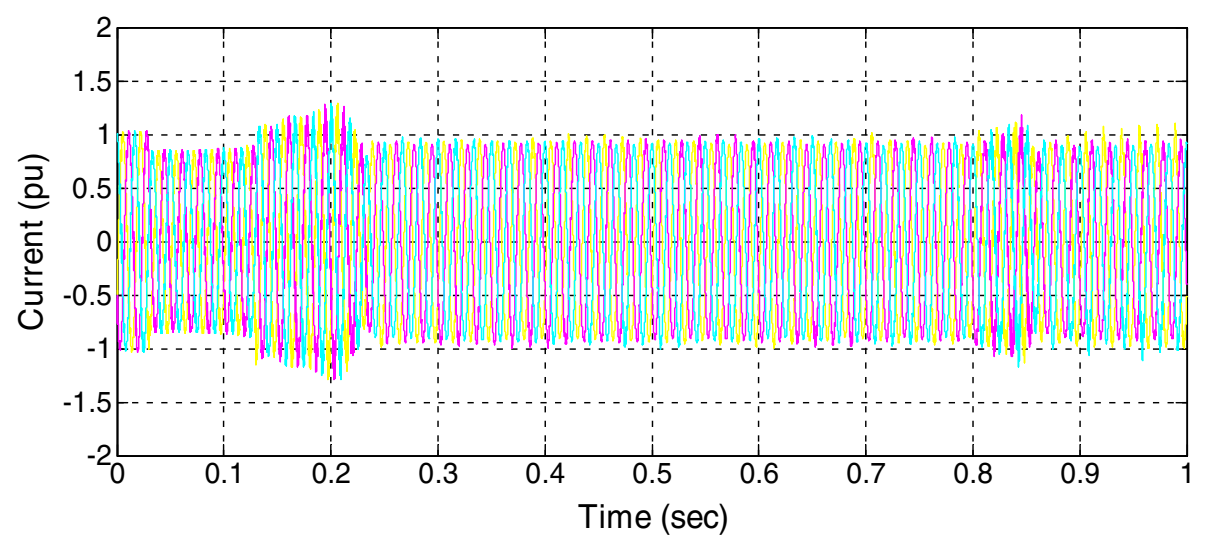

Figure 14 Matrix converter input current (traditional method).

losses, off losses, and conduction losses is achieved and is found that the net loss reduction of $32 \%$ is achieved by controlling the virtual dc link voltage using proposed SVM technique in comparison to PWM technique without virtual dc link voltage control.

As shown in Figures 3 and 4 of proposed wind energy conversion system control, the SVM technique is used to control the virtual dc link voltage. As per the analysis from the various papers, the level of voltage stress in traditional method reaches up to $1,100 \mathrm{~V}$ and above. It is also found that this value varies with change in the modulation index which is reported to vary from 0.4 to 1. In the proposed method, it has been reduced on the basis of wind profile. The virtual dc link voltage value is varied from 300 to $750 \mathrm{~V}$ in the proposed method as shown in Figure 11. In case of large wind profile disturbances, the value is reaching up to $1,200 \mathrm{~V}$ for small duration and stabilizes to the low value. As the DFIG is operating near the synchronous speed, the stress is found to be minimum and changes with respect to the deviation from synchronous speed. The acceptable level may vary up to $20 \%$ to $30 \%$ above the rated value which depends on the rating of DFIG and the power electronic converter (i.e., matrix converter).

The magnitude of the required virtual dc link voltage is controlled on the basis of wind profile and DFIG operation, i.e., slip value. Figure 11 gives the simulation results representing the corresponding value of virtual dc link voltage with respect to time. Virtual dc link voltage of the proposed modified matrix converter topology is controlled referring the wind profile. When DFIG is operating near to the synchronous speed, the required value of the virtual dc link voltage is null or the least minimum. With the variation of the wind speed with respect to time which results in the deviation of DFIG operation from synchronous speed, the required virtual dc link voltage changes as shown in Figure 11.

Figures 12 and 13 represent the common mode voltage values in traditional topology and proposed modified matrix converter topology, respectively. It is found that the peak value of CMV in proposed work is reduced as shown in Figure 13. Hence, the CMV also controlled

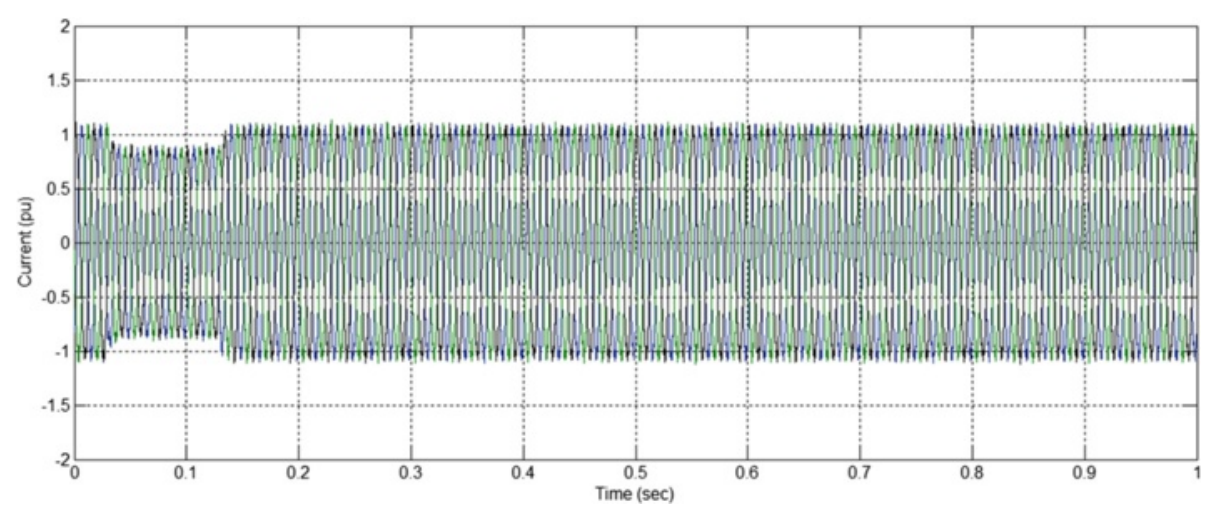

Figure 15 Matrix converter input current (proposed method). 


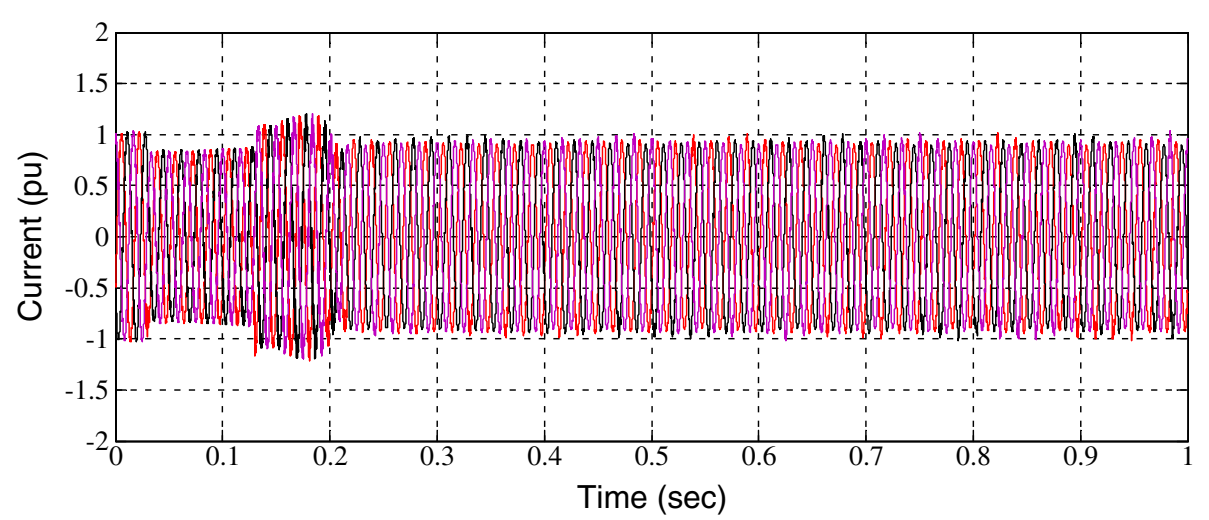

Figure 16 Matrix converter output current (traditional method).

and reduction in the peak is achieved by controlling the virtual dc link voltage using proposed SVM. It is found that common mode voltage peak value is reduced to $44 \%$ (as a percentage of CMV with respect to proposed and PWM technology) by selecting the zero space vector in the inverter stage using proposed SVM technique in comparison of using PWM technique.

Figures 14 and 15 represent the matrix converter input current waveform with traditional topology and proposed modified matrix converter topology, respectively. Figures 16 and 17 are representing the output current waveform with traditional topology and proposed modified matrix converter topology, respectively. It is observed that the input current waveform and output current waveform obtained with the proposed modified matrix converter topology is sinusoidal and distortion free.

The input and output current waveforms of proposed modified matrix converter topology show no significant deterioration. Although minor deterioration in both input and output current waveforms is observed at initial instant, but it is found to be improving very fast as shown in the result. Comparing Figures 14 and 15 for input current, it is found that the performance is improved.
Similarly for output current, the improvement can be recognized by comparing Figures 16 and 17. This is achieved using proposed technique; hence, improved power quality is achieved. It is observed that for reduced virtual dc link voltage operation, the input current ripple is slightly higher than the current ripple when maximum virtual dc link voltage is generated. This has been taken in account while designing of the input filter. Designed filters connected with matrix converter ensure that no sub-harmonics are introduced to the system and provide unity power factor at line side with no harmonic current injection. This ensures the variable wind speed operation of DFIG with more reliable and economical performance. It is also observed that input and output current of the matrix converter are at unity power factor. Harmonic content is largely minimized and the power quality is improved. Thus, there is a significant improvement in the performance of matrix converter, DFIG and overall wind energy conversion system.

\section{Conclusions}

The proposed work in this paper is replacing the power electronic converter with modified matrix converter with control of virtual dc link voltage as per the DFIG operation

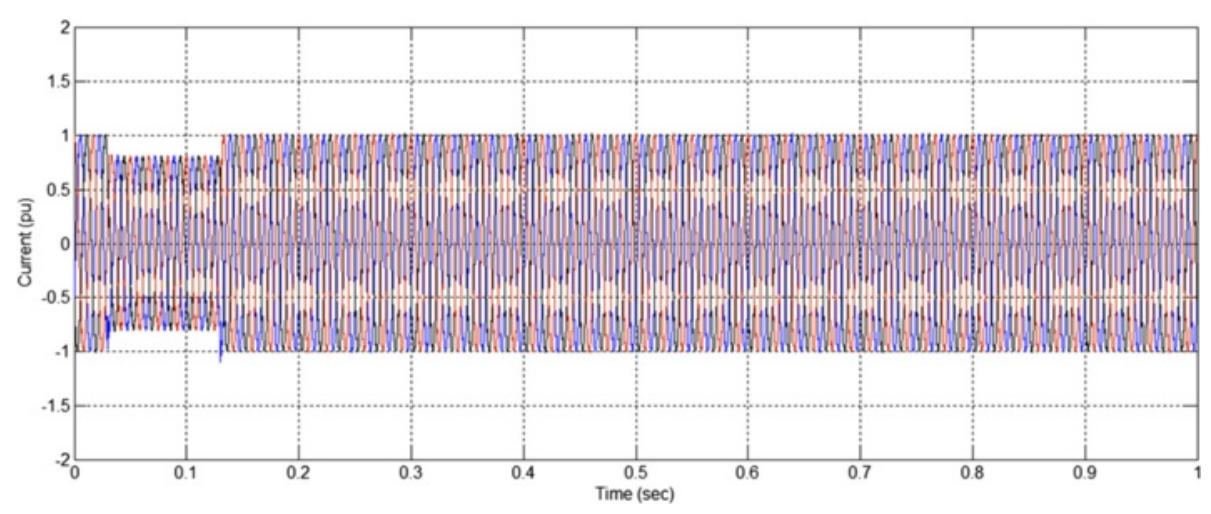

Figure 17 Matrix converter output current (proposed method). 
which is wind profile dependent. The net power converter losses have been reduced even with higher switching frequency. Reduced converter losses lower the thermal stresses across the switches. The common mode voltage peak value also decreases regardless of the output frequency. The inverter mode switching sequence affects the CMV, but the effect is not significant. Due to reduced CMV peak value, the leakage current through parasitic capacitor between stator core and stator winding reduces resulting in low thermal stress in DFIG windings. Mitigation of operational losses in matrix converter fed doubly fed induction generator for wind energy conversion system is achieved. The overall performance of the wind energy conversion system improves and ensures the reliable and quality power delivery to the connected grid with fluctuating wind characteristics.

\section{Competing interests}

The authors declare that they have no competing interests.

\section{Authors' contributions}

HA significantly contributed in conception and design of the paper. SKT contributed in the acquisition of data. HA carried out the analysis and interpretation of data and drafting of manuscript with inclusion of intellectual contents. SKT worked toward the drafting and analysis. HA and SKT are responsible for final approval, accountability, and accuracy.

\section{Acknowledgements}

Authors thankfully acknowledge the Department of Electrical Engineering, Jamia Millia Islamia, New Delhi, India for providing the infrastructure facilities like, labs, computer, softwares, internet and journal accesses, etc. to carry out and support our research work.

Received: 23 September 2014 Accepted: 26 January 2015

\section{Published online: 08 October 2015}

\section{References}

Arifujjaman, M. (2013). Reliability comparison of power electronic converters for grid-connected 1.5kw wind energy conversion system. Renewable Energy, $57,348-357$.

Ashfaq, H., Tripathi, S. K. (2012) Performance Improvement of Wind Energy Conversion System using Matrix Converter. IEEE 5th India International Conference on Power Electronics (IICPE), 1-5.

Blaabjerg, F, Liserre, M, \& Ke, M. (2012). Power electronics converters for wind turbine systems. IEEE Transactions on Industry Applications, 48(2), 708-719.

Cárdenas, R, Peña, R, Wheeler, P, Clare, J, \& Juri, C. (2012). Control of a matrix converter for the operation of autonomous systems. Renewable Energy, 43, 343-353.

Cardenas, R, Pena, R, Alepuz, S, \& Asher, G. (2013). Overview of control systems for the operation of DFIGs in wind energy applications. IEEE Transactions onlndustrial Electronics, 60(7), 2776-2798.

Cárdenas, R, Peña, R, Wheeler, P, Clare, J, Muñoz, A, \& Sureda, A. (2013a). Control of a wind generation system based on a Brushless Doubly-Fed Induction Generator fed by a matrix converter. Electric Power Systems Research, 103, 49-60.

Cárdenas, R, Peña, R, Clare, J, Wheeler, P, \& Zanchetta, P. (2013b). A repetitive control system for four-leg matrix converters feeding non-linear loads. Electric Power Systems Research, 104, 18-27.

Casadei, D, Serra, G, Tani, A, \& Zarri, L. (2002). Matrix converter modulation strategies: a new general approach based on space-vector representation of the switch state. IEEE Transactions Industrial Electronics, 49(2), 370-381.

Garcés, A, \& Molinas, M. (2012). A study of efficiency in a reduced matrix converter for offshore wind farms. IEEE Transactions on Industrial Electronics, 59(1), 184-193.

Ghatpande, O., Corzine, K., Fajri, P., Ferdowsi, M. (2013). Multiple Reference Frame Theory for Harmonic Compensation via Doubly Fed Induction Generators. IEEE Power and Energy Conference (PECI), 60-64. doi: 10.1109/PECI.2013.6506035
Ghoudelbourk, S., Bahi, T., Mohammedi, M. (2012). Improving the Quality of Energy Supplied by a Doubly-Fed Induction Generator. 2nd International Symposium on Environment Friendly Energies and Applications (EFEA), 437-442.

Hamane, B, Benghanemm, M, Bouzid, AM, Belabbes, A, Bouhamida, M, \& Draou, A. (2012). Control for variable speed wind turbine driving a doubly fed induction generator using Fuzzy-PI control. Energy Procedia, 18, 476-485.

Han, Y, Kim, S, Jung- $-k$, H, \& Lee, WJ. (2013). A doubly fed induction generator controlled in single-sided grid connection for wind turbines. IEEE Transactions on Energy Conversion, 28(2), 413-424.

Holmes, DG. (1996). The significance of zero space vector placement for carrier-based PWM schemes. IEEE Transactions on Industry Applications, $32,1122-1129$.

Lee, HD, \& Sul, SK. (2001). Common-mode voltage reduction method modifying the distribution of zero-voltage vector in PWM converter/inverter system. IEEE Transaction on Industry Applications, 37(5), 1732-1738.

Lee, MY, Wheeler, P, \& Klumpner, C. (2010). Space-vector modulated multilevel matrix converter. IEEE Transactions on Industry Applications, 57(10), 3385-3394.

Lopez Arevalo, S, Zanchetta, P, Wheeler, P, Trentin, A, \& Empringham, L. (2010). Control and implementation of a matrix-converterbased AC-ground power-supply unit for aircraft servicing. IEEE Transactions Industrial Electronics, 57(6), 2076-2084

Merahi, F, \& Berkouk, EM. (2013). Back-to-back five-level converters for wind energy conversion system with dc-bus imbalance minimization. Renewable Energy, 60, 137-149.

Ormaetxea, E, Andreu, J, Kortabarria, I, Bidarte, U, Martinez-de-Alegria, I, Ibarra, E, \& Olaguenaga, E. (2011). Matrix converter protection and computational capabilities based on a system on chip design with an FPGA. IEEE Transactions Power Electronics, 26(1), 272-287.

pdf.datasheetcatalog.com/datasheet/.../mXyzxuz.pdf

Pena, R, Cardenas, R, Reyes, E, Clare, J, \& Wheeler, P. (2011). Control of a doubly fed induction generator via an indirect matrix converter with changing dc voltage. IEEE Transactions on Industrial Electronics, 58(10), 4664-4674.

Ponmani, C, \& Rajaram, M. (2013). Compensation strategy of matrix converter fed induction motor drive under input voltage and load disturbances using internal model control. International Journal of Electrical Power \& Energy Systems, 44(1), 43-51.

Rodriguez, J., Kolar, J., Espinoza, J., Rivera, M., Rojas, C. (2010). Predictive torque and flux control of an induction machine fed by an indirect matrix converter. IEEE ICIT Proceedings, 1857-1863.

Roy, G, \& April, G-E. (1989). Cycloconverter operation under a new scalar control algorithm. 20th Annual IEEE Power Electronics Specialists Conference Proceeding, 1, 368-375

Soufi, Y, Bahi, T, Lekhchine, S, \& Dib, D. (2013). Performance analysis of DFIM fed by matrix converter and multi level inverter. Energy Conversion and Management, 72, 187-193.

Swamy, MM, Yamada, K, \& Kume, T. (2001). Common mode current attenuation techniques for use with PWM drives. IEEE Transaction on Power Electronics, 16(2), 248-55

Taib, N, Metidji, B, \& Rekioua, T. (2013). Performance and efficiency control enhancement of wind power generation system based on DFIG using threelevel sparse matrix converter. International Journal of Electrical Power \& Energy Systems, 53, 287-296.

Ugalde-Loo, CE, Ekanayake, JB, \& Jenkins, N. (2013). State-space modeling of wind turbine generators for power system studies. IEEE Transactions on Industry Application, 49(1), 223-32.

Vargas, R, Rodriguez, J, Ammann, U, \& Wheeler, P. (2008a). Predictive current control of an induction machine fed by a matrix converter with reactive power control. IEEE Transactions Industrial Electronics, 55(12), 4362-4371.

Vargas, R, Ammann, U, Rodriguez, J, \& Pontt, J. (2008b). Predictive strategy to control common-mode voltage in loads fed by matrix converters,". IEEE Transactions Industrial Electronics, 55(12), 4372-4380.

Venturini, M. (1980). A new sine wave in sine wave out, conversion technique which eliminates reactive elements. Powercon Proceeding, 7, E3/1-E3/15.

Wei, S, Zargari, N, Wu, B, \& Rizzo, S. (2004). Comparison and mitigation of common mode voltage in power converter topologies. IEEE Industry Applications Conference, 3, 1852-1857.

www.alldatasheet.com

www.datasheetarchive.com

www.datasheetarchive.com/matrix\%20converter-datasheet.html http://www.datasheetarchive.com/pdf/Datasheets-SW17/DSASW00331822.html www.igbt.cn/UserFiles/Support_IGBT/file_057.pdf 
Xiao, D., Rahman, F. (2009). An improved DTC for matrix converter drives using multi-mode ISVM and unity input power factor correction. 13th EPE Proceeding, $1-10$.

Yin, Q, Russel, JK, Thomas, AN, \& Lu, H. (2005). Analytical investigation of the switching frequency harmonic characteristic for common mode reduction modulator. IEEE Industry Applications Conference, 2, 1398-1405.

Yoon, YD, \& Sul, SK. (2006). Carrier-based modulation technique for matrix converter. IEEE Transactions Power Electronics, 21(6), 1691-1703.

Yue, F, Wheeler, P, \& Clare, J. (2006). Relationship of modulation schemes for matrix converters (pp. 266-270). Dublin, Ireland: IET PEMD Conference Proceeding.

Submit your manuscript to a SpringerOpen ${ }^{\circ}$ journal and benefit from:

- Convenient online submission

- Rigorous peer review

- Immediate publication on acceptance

- Open access: articles freely available online

- High visibility within the field

- Retaining the copyright to your article

Submit your next manuscript at $>$ springeropen.com 